\title{
Prevalence of Canine Parasitic Dermatitis in and Around Jammu
}

\author{
Sindhu Berian*, S.K. Gupta, Vijay Sharma, R.K. Bhardwaj and Shamim Ali \\ Division of Veterinary Medicine, Division of Veterinary Public Health and Epidemiology \\ Faculty of Veterinary Sciences \& Animal Husbandry, SKUAST-J, R. S. Pura, \\ Jammu-181102, India \\ *Corresponding author
}

A B S T R A C T

\begin{tabular}{|c|c|}
\hline Keywo & $\begin{array}{l}\text { Prevalence study was conducted during the period from July } 201 \text { to June 2015, on } 391 \\
\text { clinical cases of dogs presented at Referral Veterinary Hospital F. V. Sc \& A.H R. S. Pura }\end{array}$ \\
\hline $\begin{array}{l}\text { Dem } \\
\text { Sarce }\end{array}$ & $\begin{array}{l}\text { Jammu. The overall prevalance of dermatitis was } 24.55 \text { per cent }(96 / 391) \text { The prevalence } \\
\text { of parasitic dermatitis was found to be } 35.41 \text { per cent with maximum prevalence recorded }\end{array}$ \\
\hline Art & \\
\hline $\begin{array}{l}\text { Accept } \\
12 \text { July } \\
\text { Availa } \\
10 \text { Aus }\end{array}$ & $\begin{array}{l}\text { itching, and hair loss were the main clinical features of demodectic mange. While in } \\
\text { sarcoptic mange intense pruritis was found along with erythema, rashes, excoriation, crust } \\
\text { and hair loss. Lesion in parasitic dermatitis were mainly located at head and neck (36.21 } \\
\%) \text {, thorax, abdomen and groin }(24.23 \%) \text {, limbs and paws (17\%) and on elbow (13.27\%). }\end{array}$ \\
\hline
\end{tabular}

\section{Introduction}

Dogs have served as hunting companion and were used for hunting the wild animals for their food. Dogs are the closest to man because of their sophisticated social behaviors (Ugbomoiko et al., 2008). Since the beginning of civilization dog had served various purposes to man ranging from draught dogs for work, guard dogs for protection, assistant dogs to aid the blind and physically challenged, detective dogs to aid in criminal investigations and most importantly pet dogs for man companion (Bridgestome, 2004).

Pet owners have a close relationship with their dogs and often spend their leisure time cuddling them. In the pets various form of skin diseases caused by infestation of vectors like ticks, lice, fleas and mites. These all ectoparasites are responsible for canine parasitic dermatitis (demodecosis) which cause great damage to skin and also results in malodor from body. Among parasitic dermatitis, the most common ticks are Rhipicephalus sanguineus. Mange (acariasis) is a persistent contagious skin disease of animals and man caused by parasitic mites. Common mites which affect the dogs are Demodex spp, Sarcoptes scabei and Otodectic mange (Ear mites). Demodicosis is a mange caused by Demodex canis and follicular mite which infects follicles and sebaceous glands. The disease is common among canine species being manifested in three different forms (Kiminsky et al., 2010). 
Sarcoptic mange (canine scabies) is more serious, highly contagious and zoonotic. It can infect all species of animals including man. Clinical signs manifest in form of intense itch, injury to the skin, weeping skin lesions, crusts and scab formations often seen at the elbow and ear region (Nayak et al., 1997) Demodectic mange, (Red mange) is the third form and the most serious type caused by Demodex canis (Marsalla, 2010). Which is non- contagious and can only be seen in immunodeficient animals, old dogs and young puppies of about 3-months to a year infected in utero (Koutz, 1954). The mites burrow deep into the skin, feeds and secrete substance that reduces the innate resistance of the animal. The disease is thought to be hereditary often seen in oily skinned and short haired dogs. Both the sexes have the same ability to transmit genetic predisposition to demodecosis. However, Marsalla (2010) reported a higher prevalence of disease in long haired dogs.

Dogs with localized form of demodecosis develop alopecic areas around the eyelids, lips, mouth and front limb giving the animal a characteristic moth-eaten appearance. Infected puppies recover by their fourteenth month as their immunity develops. Otherwise, the disease becomes chronic and generalized showing large alopecic areas on various parts of the body which coalesce into large bald areas. The hair follicles may be plugged with debris and Demodex canis mites with draining sinus tracts emitting there by a strong foul odour. At this stage the animals may be at risk of secondary bacterial infection along with complications of pododemodecosis affecting the paws. Unlike other canines Demodex species mite Demodex corenei can reside in most superficial layer of epidermis. It is 50 per cent shorter than other form of Demodex canis (Tamura et al., 2001) Demodex injai, the large body demodex, is larger in all life stages than demodex canis (Desch and Hillier 2003).
Diagnosis is by taking deep skin scrapping in Potassium Hydroxide $(\mathrm{KOH})$ or Sodium Hydroxide $(\mathrm{NaOH})$ as $10 \%$ solution in order to digest the debris and release of mites (Kaminsky et al., 2010). However, most of times it is difficult to identify mites under the microscope and treatment is often commenced based on the obvious clinical signs. A simple way of diagnosis is by "Pedal-pinna reflex" technique where by the dog moves its hind limb in scratching motion as the examiner gently manipulate and scratches the ear.

This technique is effective for over $95 \%$ of most mange cases because these mites proliferate around the ear region at some point of time. Treatment is of a great controversy amongst veterinarians and there are different thoughts. Some group recommend small daily shots of ivermectin along with medicated bath for 3-4 weeks. Others prefer weekly injection of ivermectin shots or by oral route (Nayak et al., 1997).

As such, health status of dog as regard skin affection is of prime concern and a challenge to the field veterinarian to tackle as with. Assessment of hematobiochemical alteration with prompt therapeutic management is the dire need of hour. Therefore, an attempt is being made to study the etiology, prevalence and for evolving suitable therapeutic regimen to the treat canine dermatosis.

The present research work was undertaken as envisaged in the objective of the study to test the hemato biochemical changes and therapeutic management of canine dermatitis. The study was carried out on dogs of different age groups referred as clinical cases for treatment at Referral small animal OPD, of Faculty of Veterinary Sciences and Animal Husbandry, Sher-e-Kashmir University of Agricultural Sciences and Techonology, R.S. Pura, campus Jammu as well as dogs from adjoining areas also. 


\section{Materials and Methods}

Screening of dogs presented at small animal OPD of Referral Veterinary Hospital as well dogs from adjoining areas in and around $\mathrm{R} \mathrm{S}$ Pura was conducted from June 2014 to July, 2015. There apparently healthy dogs with no skin affection and kept under the same environmental conditions irrespective of age sex and breed were chosen randomly and kept control for the present study.

The comprehensive history in relation to onset of symptoms, original location of lesions and its type and intensity of pruritis were recorded. The entire hair coat of all the dogs were examined thoroughly in the day light for the type and location of skin lesion like papules, pustules, vesicles and scabs.

Observation for the presence or absence of gross parasites was also made. History in relation to type of feed given was also recorded. Any previous treatment given and clinical response elicited was also recorded. Entire history of each case was recorded.

\section{Collection of samples}

Affected skin was scraped with a dermal curette by a deep-skin scraping in the direction of hair growth until capillary bleeding occurred. The skin was firmly squeezed prior to and during the scraping to extrude mites from the hair follicles. Scraping was collected from different location in sufficient quantity from periphery of active lesions in sterile vials for fungal screening and in 10 percent $\mathrm{KOH}$ for detection of mites using sterilized scalpel.

Hair were plucked from the periphery of active lesions along with crust and scales if present for trichography and isolation of fungal organism. Hair around the lesion was clipped. Pustules were cleaned with 70 percent alcohol gently, allowed to dry and opened with sterile needle. Sterile cotton swab was touched to the exudate avoiding any contact with surrounding and carried to the laboratory in ice for bacteriological studies.

\section{Processing of samples}

\section{Detection of parasites}

Skin scrapping were collected in 10 percent $\mathrm{KOH}$, and transferred to test tube, subsequently, scrapping in the tube were stirred and heated gently. The stirring was done till the mixture appeared homogenous after cooling the contents of the tubes were transferred to the centrifuge tubes and centrifuge at $500 \mathrm{rpm}$ for 5 minutes. The supernatant was discarded and the sediments was spread on a glass slide for detailed microscopic examination.

For identification of gross ectoparasite, samples were collected in 70 per cent alcohol identification of mite and gross ectoparasites were done as per Soulsby (2005)

\section{Results and Discussion}

\section{Details of screened animals}

A total of 391 canines comprising of 240 males and 151 females were screened for canine dermatitis. Dermatitis was recorded only in 96 animals out of 391 undertaken for treatment from different sources in the present study.

\section{Percentage prevalence of dermatitis}

During the study period (July 2014 to June, 2015) a total of 391 dogs presented for treatment at Referral Veterinary Clinics and Teaching Hospital, (TVCC), R.S. Pura, Jammu from different sources only ninety six (24.55 per cent) were found positive for skin diseases i.e. canine dermatitis (Fig. 1; Table 1). 
Details of animals screened

\begin{tabular}{|c|l|c|c|c|}
\hline S. No. & \multicolumn{1}{|c|}{ Sources } & No. of animals Screened & Male & Female \\
\hline $\mathbf{0 1}$ & $\begin{array}{l}\text { Referral Small } \\
\text { animal OPD of }\end{array}$ & 355 & 216 & 139 \\
\hline $\begin{array}{l}\text { F.V.Sc.\& A.H. } \\
\mathbf{0 2}\end{array}$ & $\begin{array}{l}\text { Others (in and } \\
\text { around R.S.Pura) }\end{array}$ & 36 & 24 & 12 \\
\hline \begin{tabular}{l} 
Total \\
\hline
\end{tabular} & $\mathbf{3 9 1}$ & $\mathbf{2 4 0}$ & $\mathbf{1 5 1}$ \\
\hline
\end{tabular}

Table.1 Overall prevalence of canine dermatitis

\begin{tabular}{|l|l|l|}
$\begin{array}{l}\text { No. of dogs Examined } \\
\text { Screened }\end{array}$ & No. of Positive animals & Overall Prevalence (\%) \\
\hline 391 & 96 & $\mathbf{2 4 . 5 5}$ \\
\hline
\end{tabular}

Table.2 Month wise prevalence of canine dermatitis

\begin{tabular}{|l|l|l|l|}
\hline Month/Year & Total animals Screened & Positive Cases & $\begin{array}{l}\text { Prevalence } \\
(\%)\end{array}$ \\
\hline July-2014 & 47 & 20 & 42.55 \\
\hline August -2014 & 33 & 06 & 18.18 \\
\hline September-2014 & 36 & 07 & 19.44 \\
\hline Octuber-2014 & 23 & 03 & 13.04 \\
\hline November-2014 & 09 & 01 & 11.11 \\
\hline December-2014 & 10 & 01 & 10.00 \\
\hline January-2015 & 18 & 02 & 11.11 \\
\hline February-2015 & 21 & 04 & 19.04 \\
\hline March-2015 & 47 & 11 & 23.40 \\
\hline April-2015 & 49 & 14 & 28.57 \\
\hline May-2015 & 44 & 10 & 22.72 \\
\hline June-2015 & 54 & 17 & 31.48 \\
\hline Total & $\mathbf{3 9 1}$ & $\mathbf{9 6}$ & $\mathbf{2 4 . 5 5}$ \\
\hline
\end{tabular}

Table.3 Age wise incidence of screened animals

\begin{tabular}{|c|c|c|c|c|}
\hline S. No. & $\begin{array}{l}\text { Age Group } \\
\text { (years) }\end{array}$ & $\begin{array}{l}\text { Total no of } \\
\text { animal screened }\end{array}$ & $\begin{array}{l}\text { No. of animals } \\
\text { with dermatitis }\end{array}$ & Percentage \\
\hline $\mathbf{0 1}$ & $0-1$ & 207 & 44 & 21.25 \\
\hline $\mathbf{0 2}$ & $1-2$ & 81 & 22 & 27.16 \\
\hline $\mathbf{0 3}$ & $2-3$ & 57 & 17 & 29.82 \\
\hline $\mathbf{0 4}$ & $3-4$ & 46 & & 13 \\
\hline
\end{tabular}


Table.4 Age wise distribution of screened animals

\begin{tabular}{|c|c|c|c|c|c|c|}
\hline \multirow[t]{2}{*}{ S. No. } & \multirow[t]{2}{*}{ Sources } & \multicolumn{4}{|c|}{ Age group (in years) } & \multirow[t]{2}{*}{ Total } \\
\hline & & $\begin{array}{l}\text { Up to } 1 \\
\text { year }\end{array}$ & $\begin{array}{l}\text { Up to } 2 \\
\text { years }\end{array}$ & $\begin{array}{l}\text { Up to } 3 \\
\text { years }\end{array}$ & $\begin{array}{l}\text { Up to } 4 \\
\text { years }\end{array}$ & \\
\hline 01 & $\begin{array}{l}\text { Small animal } \\
\text { OPD (TVCC) }\end{array}$ & 188 & 73 & 52 & 42 & 355 \\
\hline 02 & $\begin{array}{l}\text { Others (in and } \\
\text { around R.S. Pura) }\end{array}$ & 19 & 8 & 5 & 4 & 36 \\
\hline
\end{tabular}

Fig.1 Prevalence of canine dermatitis

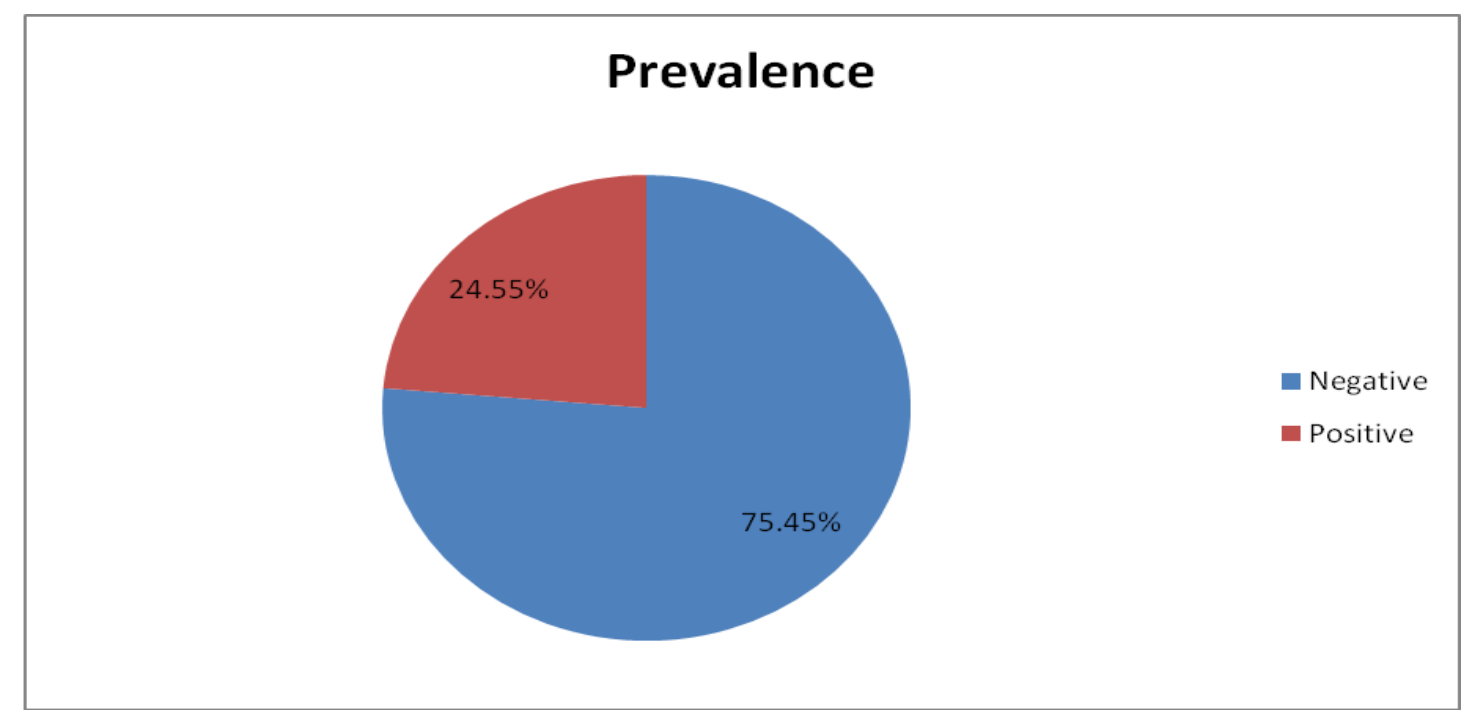

Fig.2 Month wise prevalence of canine dermatitis

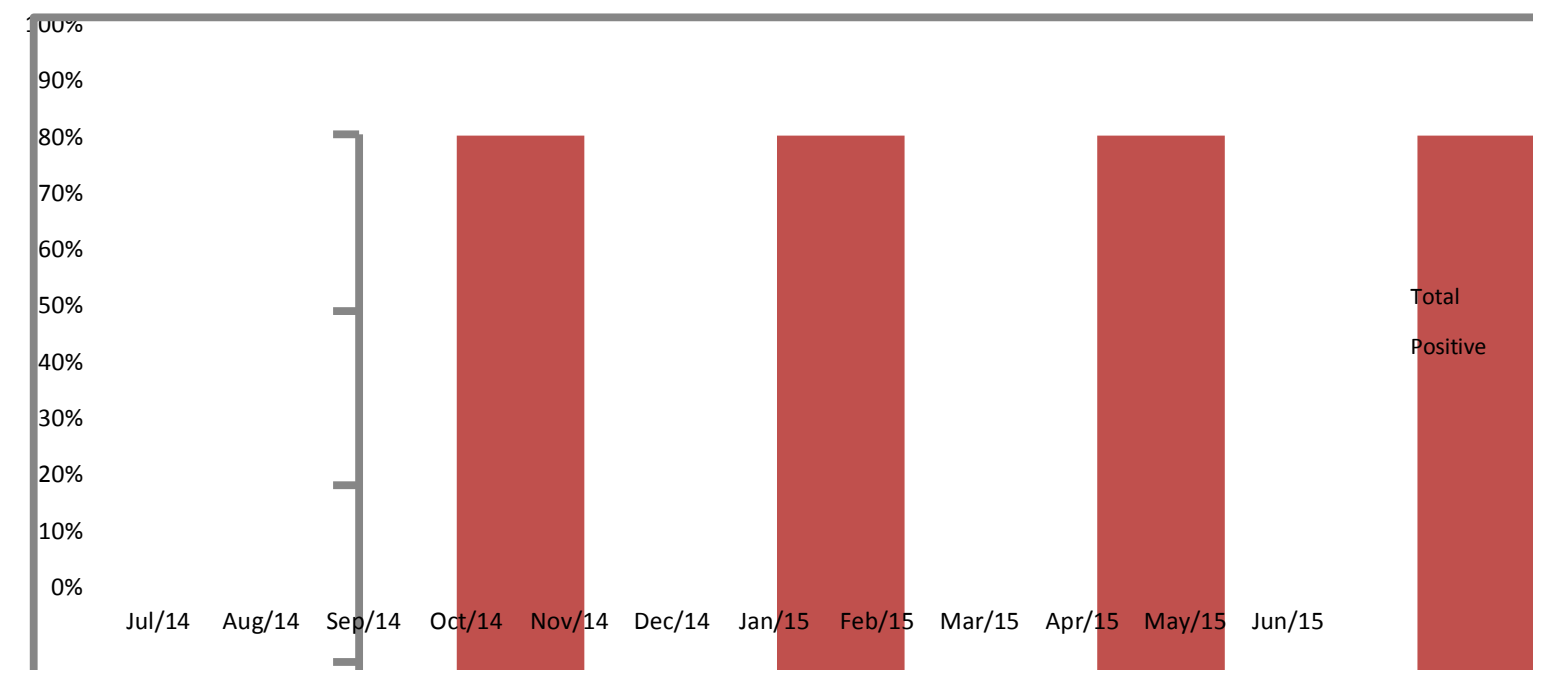


Fig.3 Age wise incidence of canine dermatitis

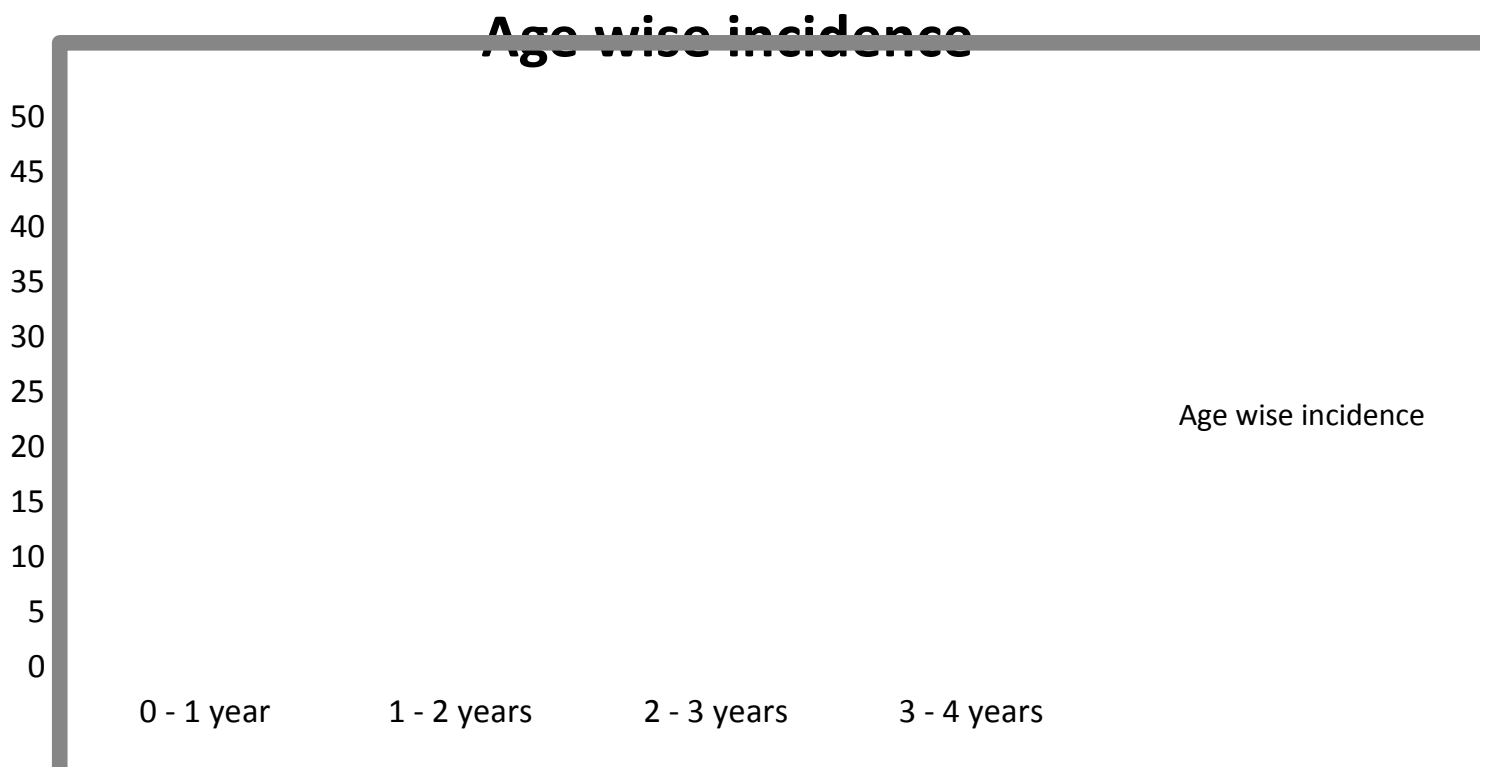

On overall basis, maximum cases 20(42.55) per cent) were recorded during July, 2014 and minimum 01(10.00) during December, 2014 and. Maximum prevalence was encountered in the dogs up to one year of age (45.83 per cent) followed by dogs two to three years (24.42 per cent)

On overall basis the maximum cases of dermatitis were of parasitic (35.41 per cent) followed by bacterial (30.25 per cent), fungal (21.87 per cent), non-specific (11.45 per cent).

\section{Parasitic dermatitis}

The overall prevalence of parasitic dermatitis was found to be 34.41 per cent with maximum prevalence in July, 2014 (42.55 per cent) and minimum in December, 2014 (Fig. 2; Table 2).

\section{Incidence of canine dermatitis}

Age wise incidence of canine dermatitis was found to be $21.25 \%$ in canines up to 1 year old, $27.16 \%$ among 1 to 2 years old, $29.82 \%$ among 2 to 3 years old and 28.26\% among 3 to 4years old.

\section{Age wise distribution}

Age wise Distribution a total of 391 canines of different age groups was screened for dermatitis. Age wise prevalence was $45.83 \%$ (44/96) up to 1year old, 22.91 (22/96) up to 2 years old, 31.06 (17/96) up to 3 years old, $29.43 \%$ (13/96) up to 4 years old (Fig. 3; Table 3 and 4$)$.

\section{Clinical signs}

The dogs with dermatological disorders revealed a range of clinical signs varying from pruritis, alopecia to pyoderma.

\section{Parasitic dermatitis}

Main clinical entity in dogs with ectoparasite infestation was pruritis. Alopecia, erythema, papule, thickening and wrinkling of skin with loss of texture were also recorded the lesion were mainly located at head/neck (36.21 per cent), thorax, abdomen and groin 
(24.23percent), limbs and paws (17 percent) elbow (13.27) and shoulder, erythema scailing, crust formation, hyper pigmentation, itching, and hair loss were the main features of demodectic mange. In sarcoptic mange intense pruritis was found along with erythema, rashes, excoriation, crust and hair loss.

Canine dermatitis is one of the most common clinical ailment directly or indirectly associated with immunodepression and number of etiological agents. Dermalogical disorders in canines assumes great importance due to their effect on the animal such as irritation, distress and offensive smell.

The present study was conducted on 391 dogs presented for health examination at Referral small animal OPD of F.V.Sc. \& A.H, R.S Pura, to investigate the possible association between history, clinical findings and laboratory findings. The study was done to isolate the organism responsible for canine dermatitis, as well as to identify predisposing factors involved in this disease. Overall prevalence of canine dermatitis during the study period was 24.55 per cent $(96 / 391)$ with maximum prevalence during July, (42.55 per cent) and minimum in December, (10.00 per cent).

\section{References}

Brigestome. 2004. Association of veterinary medical student (AVMS) 2004. Dogs As Man Companion; 1-5.

Kaminsky, A. What is the Best Treatment for Mange? Wise GEEK.com. 2010.

Koutz, F.R. 1954.Demodex folliculorum (iii) Asurvey of clinical cases in dogs. Journal of American Veterinary Medical Association 123: 131-133.

Marsalla, R. 2010. Demodicosis (Red Mange) in Dogs. Petplace.com.

Nayak, D.C., Tripathy, S.B. Dey, P.C., Ray, S.K., Mohanty, D.N., Parida, G.S., Biswal, S. and Das, M. 1997. Prevalence of canine demodicosis in Orissa (India), Veterinary Parasitology, 73: 347-352.

Soulsby, E.L.J. 2005. Helminth Arhropods and Protozoa of Domesticated Animals. Baillere Tindall.

Ugbomoiko, U. S., Ariza, L. and Heukelbach, J 2008. Parasites of importance for human health in Nigerian dogs: high prevalence and limited knowledge of pet owners. Veterinar Research; 4: 49.

\section{How to cite this article:}

Sindhu Berian, S.K. Gupta, Vijay Sharma, R.K. Bhardwaj and Shamim Ali. 2018. Prevalence of Canine Parasitic Dermatitis in and Around Jammu. Int.J.Curr.Microbiol.App.Sci. 7(08): 2420-2426. doi: https://doi.org/10.20546/ijcmas.2018.708.244 